\title{
Hemosuccus pancreaticus: a rare complication of chronic pancreatitis
}

\author{
Joana Ferreira, Amelia Brandao Tavares, Elsa Costa, Jorge Maciel
}

Centro Hospitalar de Vila Nova de Gaia/Espinho, Vila Nova de Gaia, Portugal

\section{Correspondence to}

Dr Joana Ferreira,

joanasoaresferreira@hotmail. com

Accepted 4 June 2015
CrossMark

To cite: Ferreira J, Tavares $A B$, Costa $E$, et al. $B M J$ Case Rep Published online: [please include Day Month Year] doi:10.1136/ bcr-2015-209872

\section{SUMMARY}

Hemosuccus pancreaticus is a very rare cause of gastrointestinal bleeding and it should be considered in every patient with history of chronic pancreatitis who presents with acute or intermittent gastrointestinal haemorrhage. A 54-year-old man with a history of chronic alcoholic pancreatitis was admitted to hospital for an acute exacerbation. During hospital stay, he presented with haematemesis and haemodynamic instability. Upper gastrointestinal endoscopy revealed a blood clot on Vater papilla. CT investigation showed a $4 \mathrm{~cm}$ cephalopancreatic pseudocyst and angiography identified a large pseudoaneurysm of the right gastroepiploic artery, bleeding into the pseudocysthemosuccus pancreaticus. Microcoil transcatheter embolisation was performed with success.

\section{BACKGROUND}

Hemosuccus pancreaticus occurring from pseudoaneurysm rupture into a pseudocyst is an infrequent cause of life-threatening haemorrhage. It remains a challenge in diagnosis and it should be considered in every patient with a history of chronic pancreatitis who presents with acute or intermittent gastrointestinal haemorrhage.

\section{CASE PRESENTATION}

A 54-year-old man with a history of alcohol abuse and chronic alcoholic pancreatitis, presented in the emergency room with epigastric pain irradiating to the back, and nausea. After laboratory and imaging investigation, he was admitted for an acute exacerbation of his pancreatitis.

During hospital stay, he presented with epigastric pain and haematemesis. On examination, the patient had pallor, diaphoresis, epigastric tenderness and presented haemodynamic instability (blood pressure of $83 / 41 \mathrm{~mm} \mathrm{Hg}$; pulse 112/min). Laboratory investigation revealed haemoglobin $6.3 \mathrm{~g} / \mathrm{dL}$. After resuscitation with fluid challenge and blood transfusion, an emergency upper gastrointestinal endoscopy was performed.

\section{INVESTIGATIONS}

Upper gastrointestinal endoscopy revealed a large blood clot on the Vater papilla.

CT scan of the abdomen showed two large pseudocysts: $4 \mathrm{~cm}$ at the pancreatic head and $6 \mathrm{~cm}$ at the tail of the pancreas.

Contrast CT (figures 1-3) and angiography identified a $4 \mathrm{~cm}$ pseudoaneurysm of the right gastroepiploic artery, bleeding into the cephalopancreatic pseudocyst-hemosuccus pancreaticus.

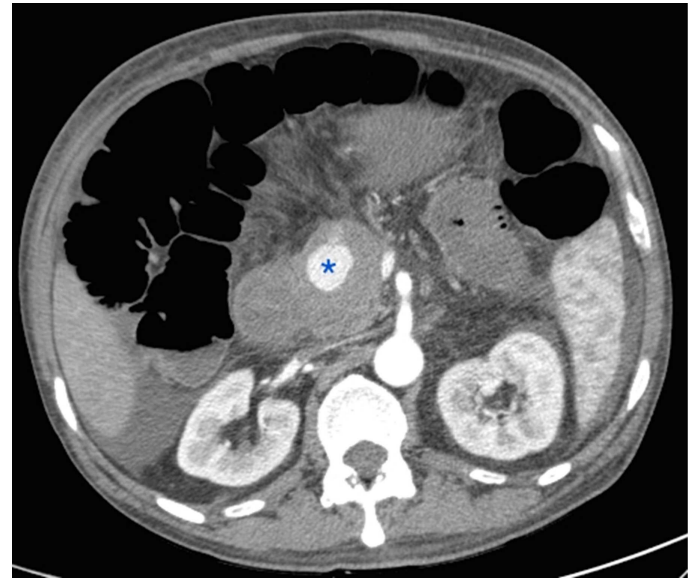

Figure 1 Axial CT scan showing the pseudoaneurysm (asterisk) within a large pancreatic pseudocyst.

\section{DIFFERENTIAL DIAGNOSIS}

- Oesophageal varices from hepatic cirrhosis and portal hypertension

- Stress ulcer

- Gastric carcinoma

\section{TREATMENT}

The patient underwent percutaneous endovascular treatment with microcoil transcatheter embolisation.

\section{OUTCOME AND FOLLOW-UP}

Percutaneous angiographic embolisation was successful, with no evidence of rebleeding.

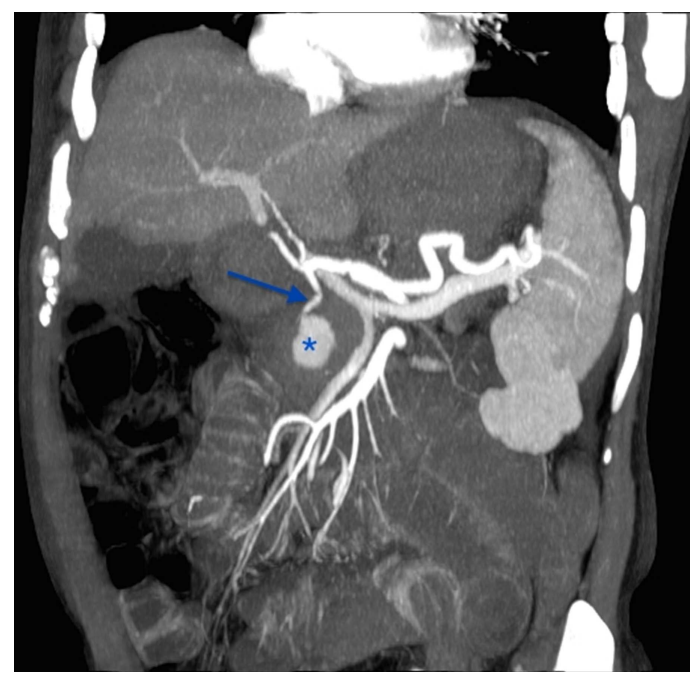

Figure 2 Coronal contrast CT identified a $4 \mathrm{~cm}$ pseudoaneurysm (asterisk) of the right gastroepiploic artery (arrow). 


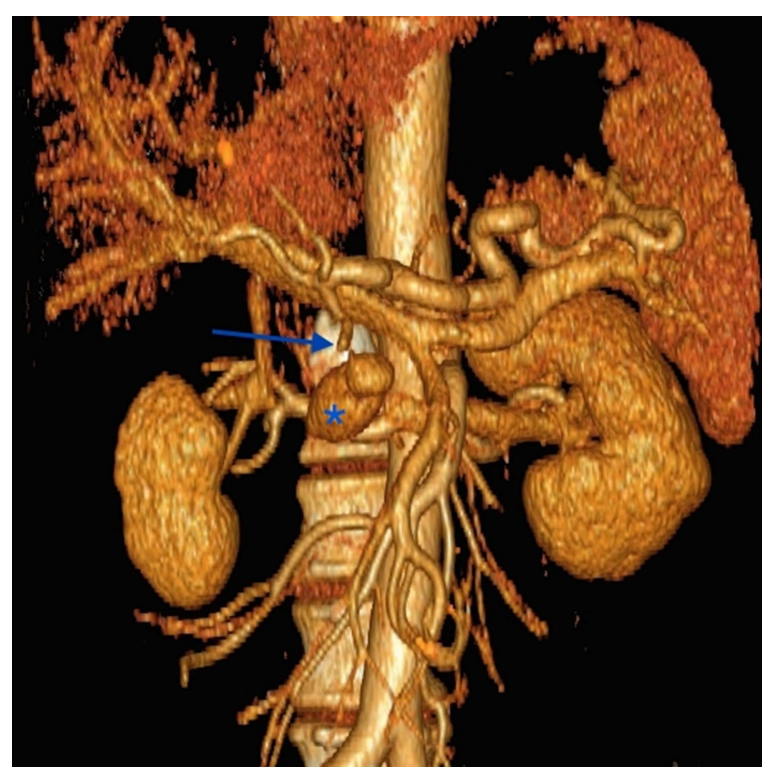

Figure 3 Tomographic reconstruction imaging exposing the pseudoaneurysm (asterisk) of the right gastroepiploic artery (arrow).

The patient was discharged after 5 days. He is on regular follow-up and continues abstinence from alcohol and is symptom-free.

\section{DISCUSSION}

Hemosuccus pancreaticus is a very rare cause of gastrointestinal bleeding. It is defined by bleeding from the Vater papilla through the pancreatic duct, ${ }^{1}$ also known as hemobilia or Wirsungorrhaghia. ${ }^{2}$ Most cases (60-80\%) are due to a strictly pancreatic origin, such as: pancreatic malformations, ductal wall ulcers caused by pancreaticolothiasis and rupture of a peripancreatic pseudoaneurysm associated with a ductal-communicating pseudocyst. $^{1} 2$

Rupture of a pseudoaneurysm into a pseudocyst is rare; in fact, reports show 6-17\% incidence of intracystic haemorrhage in patients with chronic pancreatitis. The development of a pseudoaneurysm occurs by enzymatic autodigestion and vessel wall erosion caused by necrotising inflammation due to pseudocyst formation. ${ }^{2} 3$

Splenic, common hepatic, gastroduodenal and pancreaticoduodenal arteries are most commonly involved. ${ }^{1}{ }^{2}$ Gastroepiploic arteries are rarely involved in pseudoaneurysm formation. ${ }^{4}$ If the pseudocyst has not yet formed a thick wall, the rupture of the pseudoaneurysm occurs in the peritoneal cavity or retroperitoneum, causing hemoperitoneum or retroperitoneal haematoma, respectively. On the other hand, if the pseudocyst is completely organised, the rupture of the pseudoaneurysm causes intracystic haemorrhage and hemosuccus pancreaticus. ${ }^{3}$

Intermittent colic epigastric pain followed by evidence of gastrointestinal haemorrhage (haematemesis, hematochezia or melena) ${ }^{1} 5$ within $30-40 \mathrm{~min}$ to $48 \mathrm{~h}$ is the typical clinical finding. The characteristic colic pain results from the increased intraductal pressure caused by the Wirsung obstruction by clot formation. $^{12}$

Hemosuccus pancreaticus remains a challenge in diagnosis. Upper gastrointestinal endoscopy is usually non-diagnostic and

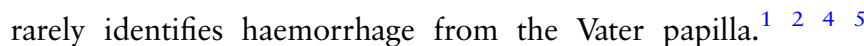
Angiography is the gold standard for the diagnosis and treatment, particularly in haemodynamically stable patients. ${ }^{1} 56$ Endovascular treatments include coil embolisation, balloon occlusion and covered stent grafting. ${ }^{2} 6$ Reports demonstrated a high success rate (75-100\%), low morbidity (14-25\%) and mortality (0-33\%) associated with percutaneous angiographic embolisation. $^{1-3}$ In fact, within 30 days, only $3 \%$ patients will require repeat endovascular intervention due to recurrent flow or bleeding. $^{2}{ }^{6}$ There is a low risk $(0.5 \%)$ of cellulitis at the femoral access site of embolisation ${ }^{6}$; nevertheless, no major septic complications were observed with endovascular treatment. ${ }^{5}$

Surgical treatment is required in $17-37 \% .^{7}$ It should be considered an alternative when radiological treatment fails or is unavailable, or when rebleeding occurs. ${ }^{1}$

Surgical treatment may be appropriate for the hemosuccus pancreaticus due to a pancreatic pseudocyst; nevertheless, the source of bleeding is usually difficult to confirm in order to determine the cutting line of the pancreas. Hence, intraoperative sonography and pancreatoscopy should be performed to confirm the origin of haemorrhage. ${ }^{4}$ Reports show a surgical success rate of $70-85 \%$, mortality rate of $20-25 \%$ and rebleeding rate of $0-5 \% .^{12} 57$

If untreated, mortality rate is up to $90 \% .^{2}$

\section{Learning points}

- Hemosuccus pancreaticus occurring from pseudoaneurysm rupture can result in life-threatening haemorrhage.

- It remains a challenge in diagnosis and it should be considered in every patient with a history of chronic pancreatitis who present with acute or intermittent gastrointestinal haemorrhage.

- Angiography showed high specificity in the diagnosis.

- Percutaneous angiographic embolisation is the gold standard treatment.

Competing interests None declared.

\section{Patient consent Obtained.}

Provenance and peer review Not commissioned; externally peer reviewed.

\section{REFERENCES}

1 Rammohan A, Palaniappan R, Ramaswami S, et al. Hemosuccus pancreaticus: 15-year experience from a tertiary care GI bleed centre. ISRN Radiol 2013;2013:191794.

2 Han B, Song ZF, Sun B, et al. Hemosuccus pancreaticus: a rare cause of gastrointestinal bleeding. Hepatobiliary Pancreat Dis Int 2012;11:479-88.

3 Carr JA, Cho JS, Shepard AD, et al. Visceral pseudoaneurysms due to pancreatic pseudocysts: rare but lethal complications of pancreatitis. J Vasc Surg 2000;32:722-30.

4 Toyoki Y, Hakamada K, Narumi S, et al. Hemosuccus pancreaticus: problems and pitfalls in diagnosis and treatment. World J Gastroenterol 2008;14:2776-9.

5 Vainas T, Klompenhouwer E, Duijm L, et al. Endovascular treatment of a hepatic artery pseudoaneurysm associated with gastrointestinal tract bleeding. J Vasc Surg 2012:55:1145-9.

6 Fankhauser GT, Stone WM, Naidu SG, et al. The minimally invasive management of visceral artery aneurysms and pseudoaneurysms. J Vasc Surg 2011;53:966-70.

7 Kappor S, Rao P, Pal S, et al. Hemosuccus pancreaticus: an uncommon cause of gastrointestinal hemorrhage. A case report. JOP 2004;5:373-6. 
Copyright 2015 BMJ Publishing Group. All rights reserved. For permission to reuse any of this content visit http://group.bmj.com/group/rights-licensing/permissions.

BMJ Case Report Fellows may re-use this article for personal use and teaching without any further permission.

Become a Fellow of BMJ Case Reports today and you can:

- Submit as many cases as you like

- Enjoy fast sympathetic peer review and rapid publication of accepted articles

- Access all the published articles

- Re-use any of the published material for personal use and teaching without further permission

For information on Institutional Fellowships contact consortiasales@bmjgroup.com

Visit casereports.bmj.com for more articles like this and to become a Fellow 